\title{
Effect of Emotional Biases on Investor's Decision Making in Nigeria
}

\author{
Ebenezer Y. Akinkoye $P h D$ \\ Professor \\ Department of Management and Accounting \\ Faculty of Administration \\ Obafemi Awolowo University \\ Ile-Ife, Osun State, Nigeria \\ E-mail: eykoye@gmail.com \\ Oluwaseun E. Bankole \\ Post-Graduate Student \\ Department of Accounting \\ Faculty of Management Sciences \\ Osun State University \\ Osogbo, Osun State, Nigeria \\ E-mail: seunbanks1993@yahoo.com
}

\begin{abstract}
The study examined emotional biases and its effect on investor's decision making in Nigeria Primary data were employed and the population consists of clients of the top 10 stockbroking firms registered by the Nigerian Stock Exchange as at $3 I^{\text {st }}$ January, 20I8. These firms were selected because they contributed to $68.72 \%$ of total value of transactions as at $3 I^{\text {st }}$ January, 20I8. Data on emotional biases and investment decision making among investors in Nigeria were obtained through structured questionnaire which was administered to 30 clients of each stockbroking firm, totalling 300. Data analysis was done using percentages and logistic regression analysis. Findings showed that emotional biases, represented by loss-aversion bias, overconfidence bias, regretaversion bias and herding bias were prevalent to Nigerian investors and also significantly influenced investor's decision making in Nigeria. The study suggests that investors should improve the understanding of various emotional biases and traits exhibited by them, adopt a suitable decision technique to avoid this and seek experts' opinion when making investment decisions.
\end{abstract}

Keywords: Emotional Bias, Loss Aversion Bias, Overconfidence Bias, Herding Bias, Regret Aversion Bias.

\section{Introduction}

One of the major causes for the emergence of Behavioural finance paradigm from an academic viewpoint is due to several difficulties confronted by the traditional finance theories in predicting investor's behaviour and understanding financial phenomenon. Behavioural finance paradigm contested the postulation of full rationality. It contended that if rationality was relaxed, several financial phenomena could be well understood. Subsequent to this assertion, various models had been postulated. Although, several models presumed that individuals only fail to update their beliefs quickly, others considered various situations where individuals were updating their beliefs rationally, but making questionable choices. Therefore, the essential aim of Behavioural finance is to complement traditional finance theories by integrating it with psychology in order to develop a better and more complete understanding of investors' behaviour in decision making process (Thaler, 2005). It should be emphasised that the major goal of behavioural finance has not been to prove any of the present traditional theories obsolete, because if those theories were not sufficient in explaining puzzling situations to a good extent, they would have been disproved and therefore ceased to exist. According to traditional finance theories, financial market had experienced what are termed as "Market Anomalies" over the years. Some of these anomalies like January affect (Rozeff \& Kinney, 1976) Monday effect (Gibbons \& Hess, I98I) Stock market overreacting to bad news (DeBondt \& Thaler, 1985) Value Investing (Fama \& French, I992). These anomalies had been studied over time, but none persisted enough for long period of time in order to be adjourned as market inefficiency. Nevertheless, existence of market anomalies has raised concerns about assumptions made by traditional finance especially investors rationality.

Market anomalies were again noted when the world economies were hit by the global recession that resulted in the Financial Crisis of 2008. This global crisis has resulted in the need to revive the question about the assumption of rationality and the possibility of the existence of a real rational economic man as proclaimed by the traditional finance theory as various signs of irrationality in decision making began to surface. According to Bernstein \& Bernstein (I996) financial evidence discloses recurring forms of irrationality, unpredictability, and ineptitude in the ways investors arrive at decisions and choices when 
confronted with market uncertainty which in-turn affect the financial market. Nofsinger (200I) noted concerning assumptions of rationality and unbiasedness of individuals, that they had been criticized by psychologists for a long time. Shanmugsundaram \& Balakrishnan (20II) asserts that the financial market volatility is constantly fuelled by irrational and sub-optimal investment decision making caused by psychological biases and emotions. Thus, the rationality of investors needs to be questioned.

The Nigeria financial market has been no exception to all these inconsistencies. According to Nwude (2012) through the duration of January I, 2008 to December 19, 2008, the All-Share-Index of the Nigeria stock market fell from an unprecedented high of 66,121.93 during the first week of March to 29,551.84 losing 48.1\% in ten months. Also, capitalization plummeted from I2.6 trillion in the same period to 6.54 trillion. Losing 6.06 trillion in ten months. Obamuyi (20I3) further buttressed the notion that the Nigeria capital market is also exposed to influences of pessimistic and optimistic sentimentalities which are created by unpredictable reactions of investors to information. He opined that investor's unpredictable reaction contributed to the crash of Nigeria stock market as at 2009. Boda \& Sunitha (2018) argued for an extensive study of investor's psychology, which they opined is bound to help improve investment decisions and in-turn benefit market efficiency. Despite these observations, the understanding of emotional biases which ensues into irrational decisions when making investment decisions are yet to be adequately explored in Nigeria, hence this study.

\section{Literature Review \\ 2.I Conceptual Review}

\section{I.I Rational Economic Man (REM)}

Traditional finance adopts the assumption that an investor gathers data, analyse it and make decisions in order to satisfy his own self-interest and utility while conforming to the axioms utility theory. Such an investor is referred to as a Rational Economic Man (REM). According to Chandra (2008) rationality can be described as being reasonable and making decisions in one's best interest. Furthermore, Somil (2007) defined rationality of investor's as an assumption in which an investor has perfect information of his business environment and makes decisions based on the sole objective of maximising profit. In addition, those investors are consistent with their decisions and will seek to attain the best possible return or gain irrespective of the available information, budget constraints and available opportunities. A REM will make choices only for his own consideration and satisfaction without considering the wellbeing of other individuals except to the level that the consideration for others will improve his own personal interest. Using an indifference curve, a REM will make the choices that will appropriate to acquire him the best return and maximum utility. The REM's indifferent curve as prescribed by Kahneman \& Tversky (1979) will possess a curve of consumption among which he is indifferent among its investments and will choose only investment mix of the curve with the highest utility and is as he is not concerned about the investment characteristic but only the returns at which on his curve of consumption will all give the best return or utility no matter the mix selected which he is indifferent about.

REM is not affected by social values unless adhering to them gives him utility or not adhering to them will cause him economic loss or disutility. A REM is governed by self-interest, perfect rationality, risk aversion and perfect information and uses this in making complex deductions, analysing possible results and selecting a course of action that will give him maximum returns or utility. The principles of a REM are consistent with the axioms of utility theory, which are, independence, completeness, continuity and transitivity and REM actions in capital market will ultimately create a very efficient financial market.

\section{I.2 Emotional Biases}

An emotion could be seen as a spontaneous reaction rather than a conscious thinking. An emotional bias could be seen as a mental state that arises as a result of intuitive decisions rather than reasonable judgement. These biases are usually hard to adjust or correct in investors because they usually emanate from intuition or impulse which although investors may wish to control them, they usually often cannot. Emotions are associated to perceptions or beliefs about objects or relations and in the world of investment and feelings which could result in investors making decisions that are suboptimal. It is therefore advisable for investors to recognise their personal emotional bias and learn to adjust or adapt with it rather than attempting to eliminate it. Biases categorized under emotional biases according to Pompian (2006) are overconfidence bias, loss-aversion bias, regret aversion bias, quo endowment bias, status bias and self-control bias.

\section{I.3 Loss Aversion Bias}

This bias was firstly identified in the works of Kahneman \& Tversky (1979) when experiment were conducted which led to the development of prospect theory. Kahneman \& Tversky (1979) describes loss aversion as an assessment of gains and losses centred on a point of reference. Loss aversion bias was derived from prospect theory which shows that individuals are inclined to avoid financial losses rather than seeking gain. Loss aversion bias lead to investors to hold onto a bad investment even when there is little chance of the investment price going back up. It also results into risk avoidance when evaluating returns, investors would rather choose a more certain low return than choosing a risky investment that may result in a loss thereby limiting the potential returns of his investment portfolio. 


\section{I.4 Overconfidence Bias}

This is a bias which explains that individuals tend to exhibit a high confidence level in their own reasoning, access to information, judgement, knowledge level and cognitive abilities. Usually, excessive optimism in personal abilities results to overconfidence. Individual investors are consistently overconfident in their capacity to outperform the capital market; athough, most falter in doing so. At the pennacle of optimism, greed causes a shift of the security's prices beyond the intrinsic value, resulting into an overpriced market. Similarly, sometimes fear shifts prices below intrinsic value, resulting into an undervalued capital market. Overconfidence however, displays both aspect of emotional and cognitive errors, nevertheless, it is categorised as an emotional bias due to the intrinsic source of this bias which are primarily emotions. There are basically three types of Overconfidence bias, which are: Certainty overconfidence, Prediction overconfidence and self-attribution bias. Both prediction and certainty overconfidence display a faulty cognition and emotional aspect like hope. In estimating probabilities, hope is an emotion that underpins probability and allow for investment decisions to be made in an overconfident state. Also, this breeds in investors' the mentality to rely on luck. When decision making process rely on good fortunes and luck instead of an actual probability analysis of an event, the result of the decision is highly probable to create a less than expected result for investors. While self-attribution bias, another form of overconfidence bias is basically rooted in emotional bias. It explains the tendency of an investor to believe or ascribe the failure or success of a decision to be attributed to his innate personal trait such as foresight, good luck, bad luck and other exogenous factors.

\section{I.5 Self-Control Bias}

This is a bias which explains individuals when they are unsuccessfully in the attainment of long-term investment objectives due to deficiency in self-discipline. Money is an area in which people display lack of self-control. For example, a person may need to save for future purposes but overwhelmed by difficulty to sacrifice current consumption due to lack of self-discipline. This bias will result into investors focusing on short-term utility rather than long-term returns. It may also lead to imbalance asset allocation which could result into a severe damage to long-term wealth as investors tend to focus on present income to be derived from investment and avoid taking into account of future growth and returns of investment.

\section{I.6 Status Quo Bias}

According to Samuelson \& Zeckhauser (1988) this bias occurs when investment decision makers disproportionately stick with an existing state of decision irrespective of the outcome that is, doing nothing or maintaining an existing decision despite the outcome. Various factors such as loyalty, complacency could result into this bias. Generally, people tend to be more comfortable keeping and maintaining a certain comfortable situation and more distant to change. This affects the ability of investors to look for opportunities in circumstances that requires change even when it is beneficial. Also, it could result into investors unknowingly maintaining a portfolio that has inappropriate risk characteristics.

\section{I.7 Regret Aversion Bias}

This aversion explains the human inclination to feel distress due to the regret for making errors, even minute errors. It is a mood of ex-post guilt towards decisions which result into a sub-optimal outcome. Individuals tend to simply avoid the pain of regret associated with sub-optimal decisions. If one wishes to avoid the pain of regret, one may alter one's behaviour in ways that could be unreasonable and irrational.

Regret aversion bias is a form of emotional bias where people tend to avoid decision making out of fear concerning a probably poor outcome. Investors exhibiting regret aversion usually avoid decisive action due to fear. These investors consider that in hindsight, whatever decisions they make could prove sub-optimal (Pompian, 2006). It result into holding onto losing stock for too long so as to prevent admitting fault or mentally acknowledging losses on security. Keoning (I999) further argued that regret aversion could initiate a herding behaviour and this may result into underperformance of investment goal and return potential.

\subsubsection{Herding Bias}

According to Hirshleifer \& Teoh (2003) this is a bias that result into a collective imitation by investors leading to a convergence of action. It is a common investment bias in which individuals lean towards a majority decision usually due to peer pressure. One key cause of this is due to the sociable nature of people and that people are inclined to seek mental acceptance and acknowledgement from each other rather than standing out. Furthermore, investors tend to belief that large groups are very unlikely to be wrong which makes most investors to grow an illusion that the large group termed as the herd could possess an information that he doesn't. An examination of herding behaviour was done by Economou et al. (2010) using data obtained from the Spanish, Greek, Portuguese and Italian capital market for the years 1998 to 2008. The study the existence of asymmetric herding behaviour associated with market returns, returns volatility and trade volume. They found evidence of existence of herding in this developed economies especially during the financial global crises of 2008 . 


\subsection{Theoretical Framework}

\subsection{Prospect Theory}

Prospect theory was established as an alternative to the expected utility theory. It was propounded by Economou et al. (20I0). It describes the way people make decisions especially in situations where they are to choose amongst alternatives that involve risk and uncertainty in anticipation of potential losses and gains. This theory accommodates the perception of individuals towards framing bias, that is, view of decisions as to either gains or losses and weighting uncertain outcomes. Similarly, it proposed the understanding of individual decision making while explaining the effect of the concept and importance of mental framing on individual decisions.

Prospect theory was founded on the descriptive analysis of how choices are being made. Kahneman \& Tversky (I979) identified two phases in decision making process: a first phase known as the editing or framing phased and the second phase known as the evaluation. The editing phase consists of the preliminary analysis of a prospect using heuristics to make acceptance or rejection decisions on available choices. This is usually a simple representation of the prospect of the choices available. Subsequesntly in the second phase, the edited propective choices are then evealuated and the choice with the most perceived prospect is then accepted and selected. The major role of the first phase is to help organise the available choices in other to easily evaluate them in the second phase. Prospect theory further clarifies an apparent deviation in investment decision making by investors from the rational traditional finance theories. Deviations exhibited by individuals when they simultaneously make insurance investment on properties (low probability of loss and risk averse) and also, buy lottery tickets (high probability of loss and risk seeking).

\subsection{Empirical Review}

Economou et al. (2010) using data obtained from the Spanish, Greek, Portuguese and Italian capital market for the years 1998 to 2008. The study the existence of asymmetric herding behaviour associated with market returns, returns volatility and trade volume. They found evidence of existence of herding in this developed economies especially during the financial global crises of 2008.

Likewise, Hoffmann et al. (2010) analysed the systematic difference in investors' objectives and how investment strategies affect portfolios selection and returns. They analysed transaction records of sampled of investment clients ( 65,325 individual 23 accounts with over nine million trades from January 2000 until March 2006), from the largest online broker in The Netherlands. It was observed that investors who rely on critical analysis have higher objectives, turnover, tend to take more risks, are more overconfident, and further outperform investors who rely on technical analysis. The findings of the study further provide support for the behavioural approach to portfolio theory and shed new light on the traditional approach to portfolio theory.

Sukanya (2015) studied the influence of behavioural biases on portfolio creation and investment decision making process of investors in India. This research reviewed variances between modern finance theories and classical finance theories in investment decision making and likewise behavioural biases affecting investment decisions. The study examined behavioural biases like overconfidence, anchoring bias, confirmation bias, hindsight bias, gamblers fallacy, and herding bias which were identified to have significant effect on the investment decision making process of investors in India.

Ibrahim \& Umar (2017) studied behavioural factors and its effect on the performance of investment in the capital market in Nigerian. It concluded that investment decision making were significantly swayed by prospect factors, heuristic, rationality and herding among Nigerian individual investors. It further recommends that investors should make proper research into cognitive errors and emotional biases in other to reduce the negative effects of behavioural biases when making investment decisions.

Ceschi et al. (2018) examined the relationship and effect between heuristics and biases by aggregating their effects on rationality. The study concluded that heuristics and biases effect could be classified into majorly three effects that is, the mindware gap, valuation effect biases and anchoring and adjustment. They further concluded that, personality, age, gender and education level have a role in the form of biases exhibited by various individuals and a proper decision making strategy could significantly help in improving investment decision making.

Shah (2019) examined the effect of elf attribution bias and overconfidence on perceived market efficiency in Pakistan. The studies investigation revealed that self-attribution and overconfidence affect perceived market efficiency negatively and further recommended that increase in personal knowledge of investors about behavioural biases and conducting a substantial survey of investment prospects could help reduce the negative effect of various biases and heuristics on investment decisions which subsequently enhance market efficiencies.

\section{Methodology}

This study used primary data. The population consisted of clients of the top 10 stockbroking firms registered by the Nigerian Stock Exchange as at $3 I^{\text {st }}$ January, 20I7. These IO firms were selected because they constituted $68.72 \%$ of total value of transactions as at $3 \mathrm{I}^{\text {st }}$ January, 20I7. Data on effect of emotional biases on investment decision making among investors in 
Nigeria were obtained through structured questionnaire which was administered to 30 clients of each stockbroking firm, totalling 300 . The data were analysed using simple percentage and binary logistic regression.

In examining the effect of emotional biases on investor's decision, the following variables were used to capture emotional biases; Loss Aversion Bias (LOSS), Overconfidence Bias (OVACO), Herding Bias (HERD), Regret-aversion Bias (REG), Status-Quo Bias(STATUS), Self-control (SELFCO). The study adopted a model in line with Ishaya et al. (2017) in examining the influence of cognitive errors on investment decision. The data were analysed using binary logistic regression analysis.

\section{I Validity of Research Instrument}

The internal consistency of the instrument was determined using Cronbach's Coefficient Alpha which indicates a Cronbach alpha of 0.818 . The collected data were obtained from 28 respondents from two firms not included in the sample used for the research. The degree of reliability of the research instrument were analysed using Pearson Product Moment Correlation Coefficient (PPMC). The study indicates the scale of all the items are within the satisfactory parameters. The estimate Cronbach's alpha is above the .80 which indicates good reliability.

\subsection{Model Specification}

The study adopted model in line with Ishaya et al. (2017) in examining the effect of emotional bias on investment decision. Emotional Bias were measured by Loss Aversion bias (LOSS), Overconfidence bias (OVACO), Herding bias (HERD), Regretaversion bias (REG), Status-Quo bias (STATUS) and Self-control bias (SELFCO).

Econometrically, the relationship between emotional biases and investor's decision can be given as;

$\mathrm{INV}=\mathrm{f}$ (emotional biases)

$\mathrm{INV}=\mathrm{f}$ (Loss Aversion, Overconfidence, Herding, Regret-aversion, Status-Quos, Self-control)

$$
\begin{aligned}
I N V_{t}=\beta_{o_{t}} & +\beta_{I} \text { LOSS }_{t}+\beta_{2} \text { OVACO }_{t}+\beta_{3} H E R D_{t}+\beta_{4} R E G_{t}+\beta_{5} S T A T U S_{t} \\
& +\beta_{6} S E L F C O_{t}+\varepsilon
\end{aligned}
$$

Where; $\beta_{0}, \beta_{1}, \beta_{2}, \beta_{3}, \beta_{4}, \beta_{5}, \beta_{6}$ were coefficients in the model and $\varepsilon$ is the residual value.

INV = Investor's Decision Making;

LOSS = Loss-Aversion bias;

OVACO $=$ Overconfidence bias;

HERD = Herding bias;

REG = Regret-Aversion bias;

STATUS $=$ Status-Quo bias;

SELFCO $=$ Self-Control bias; $\beta_{0}, \beta_{1}, \beta_{2}, \beta_{3}, \beta_{4}, \beta_{5}, \beta_{6}>0$

These variable were captured on the questionnaire using a 5-point Likert scale namely; $\mathrm{SD}=$ Strongly Disagree, $\mathrm{D}=$ Disagree, $\mathrm{N}=$ Not sure, $\mathrm{A}=$ Agree, $\mathrm{SA}=$ Strongly Agree

\section{Result Interpretation and Discussion of Findings}

\begin{tabular}{|c|c|c|c|c|c|}
\hline Emotional Biases on Investment Decision Making & $\begin{array}{l}\text { Strongly } \\
\text { Disagree }\end{array}$ & Disagree & Not Sure & Agree & $\begin{array}{l}\text { Strongly } \\
\text { Agree }\end{array}$ \\
\hline $\begin{array}{l}\text { Investment in a losing stock or selling off a gaining stock is } \\
\text { justifiable }\end{array}$ & $40(2 \mathrm{I} .4 \%)$ & $43(23.0 \%)$ & $38(20.3 \%)$ & $50(26.7 \%)$ & $16(8.6 \%)$ \\
\hline It is better to trust in personal analysis than a financial analyst & $4 \mathrm{I}(2 \mathrm{I} .9 \%)$ & $39(20.9 \%)$ & $33(17.6 \%)$ & $58(31.0 \%)$ & $16(8.6 \%)$ \\
\hline $\begin{array}{l}\text { It is advisable to invest in an investment if most of your colleagues } \\
\text { and friends considered by you to financial experts are investing in } \\
\text { it }\end{array}$ & $25(13.3 \%)$ & $49(26.1 \%)$ & $36(19.1 \%)$ & $59(3 \mathrm{I} .4 \%)$ & $\begin{array}{l}19 \\
(10.1 \%)\end{array}$ \\
\hline On average, you belief you predict share prices better than others & $16(8.7 \%)$ & $30(16.3 \%)$ & $64(34.8 \%)$ & $60(32.6 \%)$ & $\mathrm{I} 4(7.6 \%)$ \\
\hline Sell-off investment if there is a major crash in financial market & $\mathrm{I} 4(7.8 \%)$ & $46(25.6 \%)$ & $24(\mathrm{I} 3.3 \%)$ & $58(32.2 \%)$ & $\begin{array}{l}38(21.1 \% \\
)\end{array}$ \\
\hline
\end{tabular}

Table I. Effect of Emotional Biases on Investment Decision Making 


\begin{tabular}{llllll}
\hline $\begin{array}{l}\text { It is a good decision to have a standard mix of investment } \\
\text { portfolio always }\end{array}$ & $6(3.2 \%)$ & I8 (9.6\%) & $29(\mathrm{I} 5.4 \%)$ & $78(41.5 \%)$ & $\begin{array}{l}57 \\
(30.3 \%)\end{array}$ \\
\hline $\begin{array}{l}\text { It is a good decision to cut down long term investment like } \\
\text { retirement fund to satisfy immediate like present consumption }\end{array}$ & $32(17.0 \%)$ & $42(22.3 \%)$ & $26(\mathrm{I} 3.8 \%)$ & $56(29.8 \%)$ & $32(17.0 \%$ \\
\hline
\end{tabular}

Table 2. Logistic Regression Result

$$
\text { Source: Field Survey (2017) }
$$

\begin{tabular}{lllll}
\hline Variable & $\boldsymbol{\beta}$ & $\mathbf{Z}$ & Sig. & Exp( $\boldsymbol{\beta})$ \\
\hline LOSS & $.38 \mathrm{I}$ & 3.986 & .046 & 1.464 \\
\hline OVACO & -.657 & $10.72 \mathrm{I}$ & $.00 \mathrm{I}$ & .518 \\
\hline HERD & .580 & 10.300 & .001 & 1.786 \\
\hline REG & -.375 & $3.68 \mathrm{I}$ & .050 & .688 \\
\hline STATUS & $-.24 \mathrm{I}$ & .522 & .470 & .786 \\
\hline SELFCO & .080 & .202 & .653 & 1.084 \\
\hline Constant & .375 & 4.394 & .036 & 1.455 \\
\hline
\end{tabular}

Source: Logistic Regression Result Analysis (2017)

Table 3. Model Summary

\begin{tabular}{llll}
\hline \multicolumn{2}{l}{ Model Summary } & & \\
\hline Step & -2 Log likelihood & Cox \& Snell R Square & Nagelkerke R Square \\
\hline I & I89.039 & .168 & .226 \\
\hline a. Estimation terminated at iteration number 4 because parameter estimates changed by less than $.00 \mathrm{I}$. \\
\hline
\end{tabular}

Source: Result Analysis (2017)

The study examined the effect of emotional biases on investment decisions in Nigeria, six emotional biases were tested for namely; Loss aversion, Overconfidence Bias, Herding, Regret Aversion, Status Quo bias and Self-Control bias. All the emotional biases tested showed a moderate odd of occurrence among investors in Nigeria and they also exhibited a significant level of relationship with investment decision except status quo bias and self-control bias, The exhibiting of emotional biases of investors indicated by Subash (2012); Sukanya (2015) in their study further buttresses the conclusion of this study on emotional biases. Emotions compromises rationality which is an important factor in making investment decisions. The exhibition of these biases can lead to overtrading, holding on to excessively risky portfolios, excessively holding on to losing stock, selling off gaining investment to early, making investment decisions without analysis and ultimately making sub-optimal investment decisions. It should be noted that emotional biases are hard to correct, investors must find a way of adapting and factoring them in when making investment decisions.

\section{Conclusion and Recommendations}

Emotional biases indicate that investor's decisions are not easily predictable and are subject to factors that vary among investors. Exhibition of emotional biases by Nigerian investors indicate that investment decisions are subjected to various personal sentiments exhibited by them and are such bound to make irrational decisions which in turn result in market inefficiency. This affirms the conclusions of Ishaya et al. (2017); Ibrahim \& Umar (2017) concerning investors rationality in Nigeria and furthermore, this aligns with the findings of Economou et al. (2010); Subash (2012); Sukanya (2015); Shah (2019) concerning effects investors of emotional biases on investment decision making process.

Therefore, this study recommends that investors should get abreast of various emotional traits and biases that they possess and develop a suitable system to avoid or adapt to them. Investors should seek expert advice and second opinion on investment opportunities rather than depend on person intellect which is bound to be affected by emotional traits. It should be noted that emotional biases are difficult to overcome; therefore a proper analysis system should be developed and employed by investors when making investment decisions.

Furthermore, it is recommended that further studies should take more psychological or behavioural approach where a well-designed experiment would be a suitable form of data collection rather than a modelled approach as emotions are highly subjective and varies among respondents. As such, emotions could not be easily captured nor predicted by a model. 


\section{References}

Bernstein, P. L., \& Bernstein, P. L. (I996). Against the Gods: the Remarkable Story of Risk. New York: John Wiley \& Sons.

Boda, R. J., \& Sunitha, G. (2018). Investor's Psychology in Investment Decision Making: A Behavioural Finance Approach. International Journal of Pure and Applied Mathematics, II9(7), I253-I26I. Retrieved from url: http://www.ijpam.eu

Ceschi, A., Costantini, A., Sartori, R., Weller, J., \& Di Fabio, A. (2018). Dimensions of decision-making: An evidence-based classification of heuristics and biases. Elservier, I-I3. doi:https://doi.org/I0.I0I6/j.paid.2018.07.033

Chandra, A. (2008). Decision Making in Stock Market: Incorporating Psycology in Finance. National Conference: FFMI 2008 IIT Kharagpur, I-29. Retrieved from https://papers.ssrn.com/sol3/papers.cfm?abstract_id=I50I72I

DeBondt, W., \& Thaler, R. (I985). Does The Stock Market Overreact? Journal of Finance, 793-805.

Economou, F., Kostakis, A., \& Philippas. (2010). An Examination of Herding Behaviour in Four Mediterranean Stock Markets. University of Glasgow: Unpublished Journal.

Fama, E., \& French, K. (1992). The Cross Section of Expected Stock Returns. Journal of Finance, 47(2), 427-465.

Gibbons, M., \& Hess, P. (I98I). Day of The Week Effects and Asset Returns. Journal of Business, 54, 579-596.

Hirshleifer, D., \& Teoh, S. (2003). Herd Behaviour and Cascading in Capital Markets: A Review and Synthesis. European Financial Management, 9 (I), 25-66.

Hoffmann, A., Shefrin, H., \& Penning, J. (2010). Behavioural Portfoilio of Individual Investor. Maastrictch University and Santa Clare University: Working Paper.

Ibrahim, U. A., \& Umar, F. F. (2017). Investigating the Effects of Behavioural Factors on Investment Performance in Nigerian Capital Market. Nile Journal of Business and Economics, 3(7), 65-82.

Ishaya, D. M. (2017, 4). Influence of Cognitive Biases on Investment DEcision-Making in Propert Market in Plateau State, Nigeria. International Journal of Social Sciences and Information Technology, 3(I), I523-I540. Retrieved from http://ir.jkuat.ac.ke/handle/I23456789/4580

Kahneman, D., \& Tversky, A. (1979). Prospect Theory: An Analysis of Decision Under Risk. Econometrica: Joumal of the Econometric Society, 47(2), 263-29I.

Keoning, J. (1999). Behioural Finance: Examining Thought Processes for Better Investing. Trust and Investments, 60, I7-23.

Nofsinger, J. (200I). Investment Madness: How Psychology Affects Your Investing and What To Do About It. New Jersey: Prentice Hall.

Nwude, E. (2012). The Crash of the Nigerian Stock Market: What Went Wrong, The Consequences and the Panacea. Developing Country Studies, 2(9), I05-I 17.

Obamuyi, M. T. (2013). Factors Influencing Inveestment Decision in Capittal Market: A Study of Individual Investors in Nigerian. Organisations and Markets in Emerging Economics, 4(I), I4I-I6I.

Pompian, M. M. (2006). Behavioural Finance and Wealth Management: How to Build Optimal Portfolio for Privatee Clients. New Jersey: John Wiley and Sons, Inc. Retrieved from http://library.perbanas.ac.id/images/book/behavioralfinance.pdf

Rozeff, M., \& Kinney, W. (1976). Capital Market Seasonality: The Case of Stock Returns. Journal of Financial Economics, 3, 379-402.

Samuelson, W., \& Zeckhauser, R. (1988). Status Quo Bias in Decision Making. Journal of Risk and Uncertainty, I(I), 7-59.

Shah, W. A. (2019). The impact of self-attribution bias and overconfidencee bias on perceived market efficiency. Islamabad: Capital University of Science and Technology. Retrieved from https://ssm.com/abstract=34I727 I

Shanmugsundaram, V., \& Balakrishnan, V. (201 I). Investment Decisions - Infuence of Behavioural Factors. Indian Journal of Finance, 5(9), 25-34.

Somil, N. (2007). Investigating Factors Affecting the Investment Decsions in Residential Development. Nottingham: University of Nottingham.

Subash, R. (2012). Role of Behavioural Finance in Portfolio Investment Decisions: Evidence From India. Prague: Published Thesis. Retrieved from https://dspace.cuni.cz/handle/20.500.I I956/43I50

Sukanya, R. (2015). Impact of behavioural Biases in Portfolio Investment Decsion Making Process. International Journal of Commerce, BUsiness and Management (IJCBM), 4(4), 2319-2828.

Thaler, R. (2005). Advances in Behavioural Finance. USA:Princeton University Press, 2.

\section{Copyrights}

Copyright for this article is retained by the author(s), with first publication rights granted to the journal. This is an open-access article distributed under the terms and conditions of the Creative Commons Attribution license (http://creativecommons.org/licenses/by/4.0/). 